\title{
STRATEGI PERUSAHAAN MELALUI CI TRA MEREK, KUALITAS PELAYANAN DAN WORD OF MOUTH TERHADAP KEPUTUSAN MENGGUNAKAN JASA KIRIM LION PARCEL CAB KARANGANYAR
}

\author{
Rohma Dhona Putra Pratama, Ida Aryati, Istiqomah \\ Universitas Islam Batik Surakarta. Jl. KH. Agus Salim No. 10 \\ Email:rohmaddhona34@gmail.com
}

\begin{abstract}
Abstrak : Penelitian ini bertujuan untuk mengetahui dan membuktikan baik secara simultan maupun parsial pengaruh Citra Merek, Kualitas Pelayanan dan Word of Mouth terhadap Keputusan Menggunakan Jasa Kirim Lion Parcel Cab Karanganyar. Penelitian ini menggunakan metode deskriptif kuantitatif. Populasi dalam penelitian ini 135 konsumen yang melakukan pengiriman barang di Lion Parcel cab Karanganyar. Pengambilan sampel sebanyak 100 responden. Pengambilan data menggunakan kuesioner. Teknik analisis data yang digunakan analisis regresi linier berganda. Penelitian ini dilakukan selama bulan November 2019 sampai Maret 2020. Hasil uji F membuktikan bahwa Citra Merek, Kualitas Pelayanan dan Word of Mouth berpengaruh positif dan signifikan terhadap keputusan menggunakan jasa kirim Lion Parcel cab Karanganyar. Citra merek secara parsial berpengaruh dan signifikan terhadap keputusan menggunakan jasa kirim Lion Parcel cab Karanganyar. Kualitas pelayanan secara parsial berpengaruh dan signifikan terhadap keputusan menggunakan jasa kirim Lion Parcel cab Karanganyar. Word of mouth secara parsial berpengaruh tetapi tidak signifikan terhadap keputusan menggunakan jasa kirim Lion Parcel cab Karanganyar. Proporsi variabel dependen (keputusan pembelian) yang dijelaskan variabel independen (citra merek, kualitas pelayanan dan word of mouth) sebesar 55,6\%. Selain itu proporsi variabel independen lainnya sebesar 44,4\% dapat dijelaskan oleh variabel lain yang tidak ada dalam penelitian ini.
\end{abstract}

Kata kunci : citra merek, kualitas pelayanan, word of mouth, keputusan pembelian

\begin{abstract}
This study aims to determine and prove both simultaneously and partially the influence of Brand Image, Service Quality and Word of Mouth on the Decision to Use Services to Send Lion Parcel Karanganyar Branch. This research uses quantitative descriptive methods. The population in this study were 135 consumers who delivered goods at Lion Parcel Karanganyar Branch. Taking a sample of 100 respondents. Retrieval of data using a questionnaire. Data analysis technique used is multiple linear regression analysis. This research was conducted from November 2019 to March 2020. F test results prove that the Brand Image, Service Quality and Word of Mouth have a positive and significant effect on the decision to use the Lion Parcel Karanganyar Branch service. Brand image partially influences and significantly affects the decision to use Lion Parcel Karanganyar Branch. The quality of service partially influences and significantly affects the decision to use Lion Parcel Karanganyar Branch. Word of mouth partially influences but is not significant to the decision to use Lion Parcel Karanganyar Branch. The proportion of the dependent variable (purchasing decision) explained by the independent variable (brand image, service quality and word of mouth) was 55.6\%. In addition, the proportion of other independent variables of $44.4 \%$ can be explained by other variables not present in this study.
\end{abstract}

Keywords: brand image, service quality, word of mouth, purchasing decisions 


\section{PENDAHULUAN}

Keputusan Pembelian Konsumen merupakan sebuah tindakan yang dilakukan konsumen untuk membeli suatu produk. Sebelum memutuskan menggunakan jasa, konsumen melakukan pertimbangkan dengan beberapa jasa yang sama. Setiap perusahaan pasti menjalankan berbagai cara agar konsumen memutuskan untuk memilih jasa yang ditawarkan.

Beberapa strategi perusahaan untuk mempengaruhi konsumen terdiri dari Citra Merek, Pelayanan dan Word of Mouth terhadap keputusan menggunakan jasa kirim lion parcel cab Karanganyar. Menurut (Sitio, 2019) menciptakan dan mempertahankan konsumen salah satunya melalui persaingan merek, penciptaan kesan menjadi karakteristik dasar dalam orientasi pemasaran modern dengan pemberian perhatian lebih serta penciptaan merek yang kuat.

Perusahaan jasa harus bersaing dalam memberikan layanan yang terbaik dalam rangka merangkul konsumen yang potensial. Kompetisi ini memaksa perusahaan-perusahaan jasa kurir untuk memaksimalkan kinerja agar mampu bersaing (Setiawan, 2018).

Lion parcel merupakan perusahaan jasa yang bergerak dibidang jasa pengiriman barang. Lion Parcel melayani pengiriman domestik dan internasional yang didukung oleh jaringan dan infrastruktur Lion Group sebagai salah satu maskapai penerbangan terbesar. Beberapa strategi dilakukan lion parcel untuk memenangkan pasar dan menyakinkan konsumen untuk mrmpercayai dan mengirimkan paketnya di lion parcel terutama konsumen di karanganyar.

\section{TINJAUAN PUSTAKA}

\section{Keputusan Pembelian}

Keputusan pembelian merupakan serangkaian tahapan yang dilakukan ketika konsumen mulai mengidentifikasi permasalahan, menelusuri keterangan mengenai data suatu produk dan merek serta mengevaluasi seberapa efektifitas pilihan suatu produk. Keputusan pembelian dalam tahap evaluasi, para konsumen akan membentuk daftar merek - merek yang ada didalam kumpulan pilihannya untuk membeli merek yang paling disukainya (Kotler dan Keller, 2007 : 240).

\section{Citra Merek}

Kotler dan Keller, (2007 : 346) Citra Merek adalah persepsi dan keyakinan yang dilakukan oleh konsumen, seperti tercermin dalam asosiasi yang terjadi dalam memori konsumen. Merek adalah produk atau jasa penambah dimensi yang dengan cara tertentu mendiferensiasikan dari produk atau jasa lain yang dirancang untuk memuaskan kebutuhan yang sama.

\section{Kualitas Pelayanan}

kualitas pelayanan secara sederhana dapat diartikan sebagai produk yang bebas cacat, dengan kata lain produk yang sesuai dengan standar berupa target sasaran atau persyaratan yang bisa didefinisikan, diobservasi dan diukur. Pelayanan merupakan produk-produk yang tidak kasat mata (tidak dapat diraba) yang melibatkan usaha-usaha manusia dan menggunakan peralatan (Nurlina, Milasari dan Indah, 2019).

\section{Word of Mouth}

Word of mouth adalah proses dimana informasi yang didapatkan oleh seseorang tentang suatu produk atau jasa dari interaksi sosial maupun dari pengalaman konsumsi yang diteruskan kepada orang lain. Rekomendasi dari pelanggan lain biasanya lebih dipercaya daripada kegiatan promosi yang berasal 
dari perusahaan dan dapat sangat memengaruhi keputusan orang lain untuk menggunakan atau bahkan menghindari suatu jasa (Lovelock, Wirtz dan Mussry 2010 : 216).

\section{Kerangka Pemikiran}

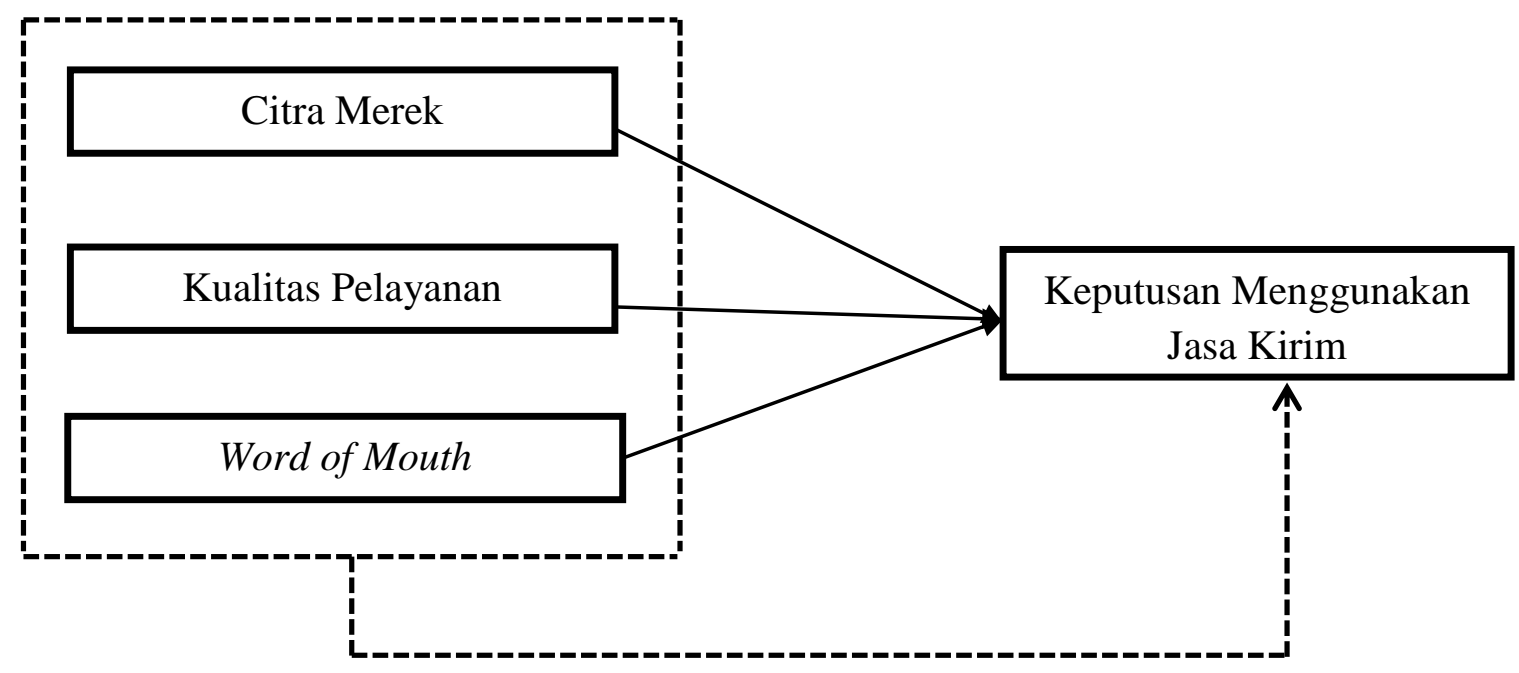

Keterangan :

: pengaruh secara parsial

: pengaruh secara bersama

\section{Hipotesis}

1) Citra Merek, Kualitas Pelayanan dan Word of Mouth secara simultan berpengaruh terhadap keputusan menggunakan jasa kirim Lion Parcel cab Karanganyar.

2) Citra Merek secara parsial berpengaruh positif dan signifikan terhadap keputusan menggunakan jasa kirim Lion Parcel cab Karanganyar.

3) Kualitas Pelayanan secara parsial berpengaruh positif dan signifikan terhadap keputusan menggunakan jasa kirim Lion Parcel cab Karanganyar.

4) Word of Mouth secara parsial berpengaruh positif dan signifikan terhadap keputusan menggunakan jasa kirim Lion Parcel cab Karanganyar.

\section{METODE PENELITIAN}

Penelitian ini menggunakan metode pendekatan kuantitatif. Semua pelanggan yang melakukan pengiriman barang di Lion Parcel cab Karanganyar menjadi populasi penelitian serta sampel yang diambil 100 konsumen, dengan teknik mengumpulkan data menggunakan kuesioner penelitian skala Likert 1-5 dan diolah menggunakan komputer program IMB SPSS Statistic 21. 


\section{ANALISIS DATA}

\section{Koefisien Determinasi}

Tabel 1. Hasil Uji Koefisien Determinasi $\left(\mathbf{R}^{2}\right)$

\begin{tabular}{|c|c|l|}
\hline Model & $\begin{array}{c}\text { Adjusted } \boldsymbol{R} \\
\text { Square }\end{array}$ & \multicolumn{1}{c|}{ Keterangan } \\
\hline 1 & 0,556 & $\begin{array}{l}\text { Varibael independen mampu } \\
\text { menerangkan variabel } \\
\text { dependen }\end{array}$ \\
\hline
\end{tabular}

Berdasarkan hasil analisis diatas maka diperoleh nilai Adjusted $R$ Square $\left(\mathrm{R}^{2}\right)$ sebesar 0,556 atau $55,6 \%$. Artinya determinasi atau sumbangan variabel citra merek, kualitas pelayanan dan word of mouth terhadap keputusan menggunakan jasa kirim lion parcel cab Karanganyar sebesar 55,6\%. Sisanya sebesar 44,4\% tidak dijelaskan dalam penelitian ini dan dapat dijelaskan oleh variabel lainnya misalnya lokasi, harga, faktor psikologis, kepercayaan dan lain sebagainya.

\section{Analisis Regresi Linier Berganda}

Tabel 2. Hasil Analisis Regresi Linier Berganda

\begin{tabular}{|c|c|c|c|c|}
\hline Variabel & B & t hitung & Sig. & Keterangan \\
\hline Citra Merek & 0,171 & 2,700 & 0,008 & Signifikan \\
\hline $\begin{array}{c}\text { Kualitas } \\
\text { Pelayanan }\end{array}$ & 0,539 & 7,620 & 0,000 & Signifikan \\
\hline $\begin{array}{c}\text { Word Of } \\
\text { Mouth }\end{array}$ & 0,056 & 0,968 & 0,336 & Tidak Signifikan \\
\hline Constant $=0,892$ & & \\
\hline
\end{tabular}
ini adalah :

Berdasarkan hasil diatas dapat dirumuskan model regresi linier berganda dalam penelitian

$$
\mathrm{Y}=0,892+0,171 \mathrm{X}_{1}+0,539 \mathrm{X}_{2}+0,056 \mathrm{X}_{3}+\mathrm{e}
$$

Berdasarkan persamaan regresi tersebut dapat diinterpretasikan sebagai berikut :

a. Nilai konstanta ( a ) sebesar 0,892 artinya apabila variabel independen yaitu citra merek, kualitas pelayanan dan word of mouth nilainya adalah 0 (nol), maka variabel keputusan pembelian (Y) akan berada pada angka 0,892 satuan.

b. Koefisien variabel citra merek $\left(b_{1}\right)$ dari perhitungan regresi linier berganda nilai koefisien (b) $=0,171$. Hal ini menunjukkan bahwa jika citra merek meningkat satu satuan, sementara variabel kualitas pelayanan dan word of mouth tetap maka keputusan pembelian akan meningkat sebesar 0,171 satuan.

c. Koefisien variabel kualitas pelayanan $\left(b_{2}\right)$ dari perhitungan regresi linier berganda nilai koefisien (b) $=0,539$. Hal ini menunjukkan bahwa jika kualitas pelayanan meningkat satu satuan, sementara variabel citra merek dan word of mouth tetap maka keputusan pembelian akan meningkat sebesar 0,539 satuan. 
d. Koefisien variabel word of mouth $\left(\mathrm{b}_{3}\right)$ dari perhitungan regresi linier berganda nilai koefisien (b) $=0,056$. Hal ini menunjukkan bahwa jika word of mouth meningkat satu satuan, sementara variabel citra merek dan kualitas pelayanan tetap maka keputusan pembelian akan meningkat sebesar 0,056 satuan.

\section{Uji Asumsi Klasik}

1) Uji Normalitas

Tabel 3. Hasil Uji Normalitas Kolmogorov Smirnov

\begin{tabular}{|c|c|c|c|}
\hline Kolmogorov-Smirnov Z & Signifikansi & Batas & Keterangan \\
\hline 0,412 & 0,996 & 0,05 & Normal \\
\hline
\end{tabular}

Dari hasil uji normalitas nilai Kolmogorov-Smirnov Z sebesar 0,412 dan nilai Asymp. Sig sebesar 0,996 lebih besar dari 0,05. Hal ini menunjukkan bahwa model regresi berdistribusi normal.

2) Uji Multikolinieritas

\section{Tabel 4. Hasil Uji Multikolineritas}

\begin{tabular}{|c|c|c|c|}
\hline Variabel & Tolerance & VIF & Keterangan \\
\hline Citra Merek & 0,723 & 1,384 & Tidak terjadi multikolineritas \\
\hline $\begin{array}{c}\text { Kualitas } \\
\text { Pelayanan }\end{array}$ & 0,738 & 1,356 & Tidak terjadi multikolineritas \\
\hline $\begin{array}{c}\text { Word Of } \\
\text { Mouth }\end{array}$ & 0,732 & 1,366 & Tidak terjadi multikolineritas \\
\hline
\end{tabular}

Dari hasil uji multikolineritas didapat nilai tolerance lebih dari 0,10 dan nilai VIF kurang dari 10. Dengan demikian dapat disimpulkan bahwa persamaan regresi tidak terdapat masalah multikolinieritas pada data penelitian ini.

3) Uji Heteroskedastisitas

Tabel 5. Hasil Uji Heteroskedastisitas Glejser

\begin{tabular}{|c|c|c|c|}
\hline Variabel & Signifikansi & Batas & Keterangan \\
\hline Citra Merek & 0,736 & $>0,05$ & $\begin{array}{c}\text { Tidak terjadi } \\
\text { heteroskedastisitas }\end{array}$ \\
\hline $\begin{array}{c}\text { Kualitas } \\
\text { Pelayanan }\end{array}$ & 0,365 & $>0,05$ & $\begin{array}{c}\text { Tidak terjadi } \\
\text { heteroskedastisitas }\end{array}$ \\
\hline Word Of Mouth & 0,317 & $>0,05$ & $\begin{array}{c}\text { Tidak terjadi } \\
\text { heteroskedastisitas }\end{array}$ \\
\hline
\end{tabular}


Dari hasil uji heteroskedastisitas diperoleh nilai signifikansi yang lebih besar dari 0,05. Maka dapat disimpukan bahwa ketiga variabel independen dalam penelitian ini tidak terdapat gejala heteroskedastisitas.

\section{Uji Hipotesis}

a. Uji F

Tabel 6. Hasil Uji F

\begin{tabular}{|c|c|c|c|c|c|}
\hline Model & F hitung & F tabel & Sig. & Std & Keterangan \\
\hline $\begin{array}{c}\text { Regression } \\
\text { Residual }\end{array}$ & 42,273 & 2,70 & 0,000 & 0,05 & $\begin{array}{c}\text { Ho ditolak, Ha } \\
\text { diterima }\end{array}$ \\
\hline
\end{tabular}

Temuan uji $\mathrm{F}$ didapat nilai $\mathrm{F}$ hitung 42,273 > F tabel 2,70. Hal ini menunjukkan bahwa semua variabel independen yaitu citra merek, kualitas pelayanan dan word of mouth berpengaruh secara simultan dan signifikan terhadap keputusan menggunakan jasa kirim lion parcel cab Karannganyar.

b. Uji t

Tabel 7. Hasil Uji t

\begin{tabular}{|c|c|c|c|c|c|}
\hline Variabel & $\mathbf{t}$ hitung & $\mathbf{t}$ table & Sig. & Std & Keterangan \\
\hline Citra Merek & 2,700 & 1,985 & 0,008 & $<0,05$ & Diterima \\
\hline $\begin{array}{c}\text { Kualitas } \\
\text { Pelayanan }\end{array}$ & 7,620 & 1,985 & 0,000 & $<0,05$ & Diterima \\
\hline Word Of Mouth & 0,968 & 1,985 & 0,336 & $<0,05$ & Ditolak \\
\hline
\end{tabular}

Temuan dari uji t dijelaskan sebagai berikut :

a) Secara individu citra merek dapat mempengaruhi keputusan menggunakan jasa kirim.

b) Secara individu kualitas pelayanan dapat mempengaruhi keputusan menggunakan jasa kirim.

c) Secara individu word of mouth tidak dapat mempengaruhi keputusan menggunakan jasa kirim 


\section{PEMBAHASAN}

\section{Pengaruh citra merek terhadap keputusan menggunakan jasa kirim lion parcel cab Karanganyar}

Berdasarkan hasil uji yang diperoleh dapat dijelaskan bahwa citra merek memiliki pengaruh yang positif terhadap keputusan menggunakan jasa kirim Lion parcel. Pernyataan konsumen memilih jasa kirim yang cepat dalam pengiriman barangnya dengan tarif yang tidak mahal dan jaminan perawatan barang yang baik sehingga barang yang akan diterima konsumennya nanti dapat diterima dengan kondisi yang bagus. Lion parcel dapat dibilang masuk dalam kriteria tersebut, dengan armada yang dimiliki sendiri maka tarif yang diberikan lion parcel lebih murah dari jasa kirim lain. Hasil penelitian ini sejalan dengan penelitian sebelumnya yang dilakukan oleh (setiawan, 2018).

\section{Pengaruh kualitas pelayanan terhadap keputusan menggunakan jasa kirim lion parcel cab Karanganyar}

Berdasarkan hasil uji yang diperoleh dapat dijelaskan bahwa kualitas pelayanan memiliki pengaruh yang signifikan terhadap keputusan menggunakan jasa kirim. Sikap ramah atau selalu memperhatikan kebutuhan dari konsumen Hal ini menjadikan konsumen merasa senang dan tidak khawatir lagi jika barang - barang kiriman tidak dapat mengantarnya sendiri. Berdasarkan uraian tersebut dapat disimpulkan bahwa dalam penelitian ini kualitas pelayanan terbukti mejadi faktor yang mempengaruhi keputusan menggunakan jasa kirim lion parcel cab Karanganyar. Hasil penelitian ini sesuai dengan penelitian yang dilakukan oleh (rohman dan andhita h, 2017).

\section{Pengaruh word of mouth terhadap keputusan menggunakan jasa kirim lion parcel cab Karanganyar}

Berdasarkan hasil uji yang diperoleh dapat dijelaskan bahwa word of mouth memiliki pengaruh tetapi tidak signifikan terhadap keputusan menggunakan jasa kirim Lion Parcel cab Karanganyar. Pelaku penggunakan jasa kirim yang sudah disarankan temannya kebanyakan dari mereka akan memilih jasa kirim yang sesuai dengan yang mereka harapkan karena harus memperhitungkan dari ongkir pengiriman, waktu, dan keamanan barangnya. Hasil penelitian ini tidak sejalan dengan penelitian sebelumnya yang dilakukan oleh (wahyuni, 2018).

\section{KESIMPULAN}

Berdasarkan hasil penelitian dan pembahasan, maka dapat ditarik beberapa kesimpulan sebagai berikut :

1) Citra merek, kualitas pelayanan dan word of mouth secara simultan atau bersama-sama berpengaruh positif dan signifikan terhadap keputusan menggunakan jasa kirim lion parcel cab karanganyar.

2) Citra merek secara parsial berpengaruh dan signifikan terhadap keputusan menggunakan jasa kirim lion parcel cab karanganyar. Hal ini menunjukkan bahwa citra merek mempengaruhi keputusan menggunakan jasa kirim lion parcel cab karanganyar.

3) Kualitas pelayanan secara parsial berpengaruh dan signifikan terhadap keputusan menggunakan jasa kirim lion parcel cab karanganyar. Hal ini menunjukkan bahwa pelayanan yang diberikan mampu mempengaruhi keputusan menggunakan jasa kirim lion parcel cab karanganyar.

4) Word of mouth secara parsial berpengaruh dan tidak signifikan terhadap keputusan menggunakan jasa kirim lion parcel cab karanganyar. Hal ini menunjukkan bahwa peran word of mouth dalam memberitakan lion parcel tidak mampu mempengaruhi secara keseluruhan keputusan menggunakan jasa kirim lion parcel cab karanganyar. 


\section{SARAN}

Berdasarkan kesimpulan di atas, maka dalam penelitian ini penulis memberikan saran-saran yang bermanfaat sebagai berikut :

1) Citra merek memiliki pengaruh yang signifikan terhadap keputusan menggunakan jasa. Sehingga hasil temuan ini dapat dijadikan perhatian agar selalu mempertahankan citra merek yang sudah dimiliki perusahaan.

2) Mempertahankan dan meningkatkan kualitas yang dimiliki karyawan dan perusahaan. Salah satunya dengan menjaga sikap ramah dan selalu memperhatikan kebutuhan yang diperlukan pelanggan.

3) Faktor word of mouth sebaiknya ditingkatkan supaya persepsi masyarakat dibenak pelanggan terhadap kepercayaan jasa kirim lion parcel meningkat. Sehingga pelanggan tidak ragu untuk melakukan pengiriman barang dan diharapkan mampu meningkatkan jumlah pelanggan yang melakukan pengiriman misalnya keamanan barang, keramahan karyawan dan penyimpanan barang hal ini akan menjadikan pelanggan merekomendasikan kepada teman - teman pelanggan lainnya.

4) Bagi peneliti selanjutnya menjadi bahan rujukan dalam melakukan proses penelitian yang berkaitan dengan citra merek, kualitas pelayanan dan word of mouth terhadap keputusan menggunakan jasa kirim lion parcel. Peneliti berikutnya agar lebih dikembangkan lagi dengan meneliti variabel lain yang belum ada dalam penelitian ini misalnya lokasi, $e$-wom, kepercayaan merek, persepsi pelanggan, faktor psikologis, effect metode pembayaran non cash dan lain sebagainya.

\section{DAFTAR PUSTAKA}

Kotler, Philip, dan Kevin Lane Keller. 2007. Manajemen Pemasaran Edisi 12. Jakarta: Erlangga.

Lovelock, Christopher, Jochen Wirtz, dan Jacky Mussry. 2010. Pemasaran Jasa Manusia, Teknologi, Strategi. Jakarta: Erlangga.

Nurlina, Milasari, dan Dewi Rosa Indah. 2019. "Pengaruh Kualitas Pelayanan, Harga dan Lokasi terhadap Keputusan Penggunaan Jasa Pengiriman Barang PT. Citra Van Titipan Kilat Kota Langsa." JURNAL SAMUDRA EKONOMIKA, VOL. 3, NO. 1, APRIL 2019.

Rohman, Altofu, dan Aglis Andhita H. 2017. “Analisis Pengaruh Citra Merek Dan Kualitas Layanan Terhadap Keputusan Pengguna Jasa Pengiriman (Study Kasus Pada Pengguna Jasa Jne Express Across Nations Cabang Nganjuk)." CAPITAL.

Setiawan, Elfa. 2018. "Pengaruh Citra Merek, Kualitas Produk Dan Persepsi Harga Terhadap Keputusan Menggunakan Jasa Kurir JNE, Agen Jasafa Jatiasih, Bekasi, Jawa Barat.” Jurnal Transparansi. Vol. 1, No. 2, Desember 2018.

Sitio, Vera Sylvia Saragi. 2019. "Pengaruh Kualitas Pelayanan dan Citra Merek Terhadap Keputusan Pembelian Pada Jasa Pengiriman Pt. TIKI.” Jurnal Ilmiah M-PROGRESS.

Wayuni, Dwi. 2018. "Analisis Pengaruh Kualitas Pelayanan, Citra Perusahaan Dan Word Of Mouth Terhadap Keputusan Penggunaan Jasa (Studi Pada Pengguna JNE di Kebumen).” Jurnal Manajemen Pemasaran. 